\title{
Synthesis and characterization of titania/graphene nanocomposite for application in photocatalysis
}

\author{
A. Aguilera-Mandujano and J. Serrato-Rodriguez \\ Instituto de Metalurgia y Ciencias de los Materiales, Universidad Michoacana de San Nicolás de Hidalgo, \\ Fco. J. Mujica S/N, Morelia, Mich., 58030, México.
}

Received 28 February 2020; accepted 26 June 2020

\begin{abstract}
Titanium dioxide has been extensively investigated as a photocatalyst for water purification, presenting limitations such as the recombination of electron-hole pairs generated by photons. The titania/graphene nanocomposites are promising materials to overcome these limitations due to the high specific area of graphene and unique electronic properties. In this work, an anatase-graphene nanocomposite was synthesized by a simple mixture assisted by ultrasound. Graphene was obtained by electrochemical exfoliation of graphite using the electrolysis technique. On the other hand, anatase was synthesized using the sol-gel method. The obtained graphene, anatase and the nanocomposite material, were characterized with the X-ray diffraction technique (DRX), scanning electron microscopy (MEB) and transmission electron microscopy (MET). Using Raman spectroscopy, it was possible to verify that the graphite exfoliated correctly producing few layer-graphene. The lamellar nanostructure of the exfoliated graphite has crystallographic planes characteristic of graphite, graphene, and graphene oxide. The presence of the anatase phase is shown in the diffraction spectrum of titania. The images obtained with SEM and TEM of the graphene sample show a layered lamellar structure, and the $\mathrm{TiO}_{2}$ images show agglomerates of ellipsoidal nanoparticles. Obtained titania nanoparticles have a size of about $6 \mathrm{~nm}$. Bandgap value for such extremely low particle size nanocomposite is around $3.6 \mathrm{eV}$ and presumably corresponds to the $\mathrm{TiO}_{2}$ (anatase) phase that surrounds the graphene. A nanocomposite model based on HRTEM observations is proposed. Considering the graphene electrical properties and the photocatalytic properties of $\mathrm{TiO}_{2}$, this nanocomposite promises to have applications in photocatalysis.
\end{abstract}

Keywords: Graphene; titania; nanomaterials; photocatalysis; composites.

El dióxido de titanio ha sido extensamente investigado como fotocatalizador para la purificación de agua; ete presenta limitantes como la recombinación de pares electrón-hueco generados por fotones. Los nanocompósitos titania/grafeno han resultado prometedores para superar estas limitaciones debido a la alta área específica del grafeno y sus propiedades electrónicas únicas. En este trabajo se sintetizó un nanocompósito anatasa-grafeno mediante una mezcla simple asistida por ultrasonido. El grafeno se obtuvo mediante la exfoliación electroquímica de grafito (electrolisis) y la anatasa se sintetizó usando el método sol-gel. El material nanocompósito, el grafeno y la anatasa obtenidos se caracterizaron con las técnicas de difracción de rayos X (DRX), microscopia electrónica de barrido (MEB) y microscopia electrónica de transmisión (MET). Mediante espectroscopia Raman se comprobó que el grafito se exfolió correctamente produciendo grafeno de unas cuantas capas. La estructura nanométrica laminar capeada del grafito exfoliado presenta planos cristalográficos característicos del grafito, grafeno y óxido de grafeno. En el espectro de difracción de la titania se observa la presencia de la fase de anatasa. Las imágenes obtenidas con el MEB y MET de la muestra de grafeno permiten observar una estructura laminar capeada y en las imágenes del dióxido de titanio se pueden distinguir aglomerados formados de nanopartículas elipsoidales. Las nanopartículas de titania obtenidas tienen un tamaño de aproximadamente $6 \mathrm{~nm}$. El valor de banda prohibida para un nanocompósito de tamaño de partícula tan extremadamente bajo es de alrededor de $3.6 \mathrm{eV}$ y probablemente corresponde a la fase $\mathrm{TiO}_{2}$ (anatasa) que rodea completamente al grafeno. Se propone un modelo de nanocompósito basado en observaciones HRTEM. Al considerar las propiedades eléctricas de grafeno y las propiedades fotocatalíticas de $\mathrm{TiO}_{2}$, este nanocompósito promete tener aplicaciones en la fotocatálisis.

Descriptores: Grafeno; titania; nanomateriales; fotocatálisis; compósitos.

PACS: 81,05.ue; 81,07.-b; 61,46.Df

\section{Introduction}

Titanium dioxide $\left(\mathrm{TiO}_{2}\right)$ has been investigated with a special interest in recent decades because it is considered the most promising material among semiconductors used in photocatalysis, due to its high photocatalytic performance, low cost, controllable structure and morphology, chemical stability, and its non-toxicity [1-3]. However, it has two main limitations: its high bandgap that is approximately $3.05 \mathrm{eV}$, and $3.20 \mathrm{eV}$ for the rutile and anatase phases, respectively. As a consequence of this relatively high bandgap, the titania can only absorb the UV light from the solar spectrum, which carries only about $4 \%$ of the incident solar energy, which considerably limits its overall photocatalytic efficiency [4] and
DOI: https://doi.org/10.31349/RevMexFis.66.610

also, the high speed of recombination of electron-hole pairs. Due to these deficiencies, many studies have been dedicated to the construction of composite materials with $\mathrm{TiO}_{2}$, particularly with graphene. It is considered an excellent base material for conversion applications and energy storage since it has very favorable properties for this type of application, such as good electrical conductivity, flexible and ultra-thin nature, chemical stability, and a high theoretical surface area of 2,600 $\mathrm{m}^{2} / \mathrm{g}$ [5-7] Consequently, it is an ideal candidate for the development of graphene-metal oxide composite nanomaterials for energy-related applications. When titania is combined with graphene, there is the possibility of improving absorption in the visible region, as has been confirmed in theoretical studies [8]. Therefore, multiple efforts have been made 
to obtain anatase-graphene nanocomposites with applications in photocatalysis. A strategy to grow graphene on a $\mathrm{TiO}_{2}$ (anatase) nanosheet via an ambient pressure chemical vapor deposition method using acetylene as a precursor was developed [9]. Sandwich structures of mesoporous anatase sheets and reduced graphene oxide have been obtained to be applied as electrodes in lithium-ion batteries [10]. These nanocomposites were easily synthesized from tetrabutyl titanate by acid-assisted hydrolysis and a subsequent thermal reduction process. $\mathrm{TiO}_{2}$ (anatase)/graphene nanocomposites were also synthesized by thermal plasma, dielectric barrier discharge, and heat treatment [11]. This method allowed to obtain well dispersed anatase nanoparticles below $50 \mathrm{~nm}$ and few-layer graphene nanosheets. Titania/graphene hybrids were synthesized by self-assembly and gas reduction in a hydrothermal system [12]. The method was based on electrostatic attraction between positively charged titanium glycolic acid and negatively charged graphene oxide in an aqueous medium. The ultrathin and flexible graphene layers were distributed around the surface of titania nanospheres, resulting in a new interface between titania and graphene.

In this work, the synthesis of an anatase-graphene nanocomposite is proposed, having as its main characteristic, the extremely small size of the $\mathrm{TiO}_{2}$ nanoparticles synthesized by the sol-gel method, the production of few-layer graphene by electrochemical exfoliation and the simplicity of the synthesis of the nanocomposite with ultrasonic mixing. A fixed $50 / 50 \mathrm{wt} \%$ graphene $/ \mathrm{TiO}_{2}$ phase ratio was used in an attempt to understand how both phases interact. Due to the combination of the electrical properties of zerobandgap graphene and the photocatalytic properties of $\mathrm{TiO}_{2}$, this nanocomposite promises to have applications in photocatalysis.

\section{Methodology}

\subsection{Synthesis of graphene/ $\mathrm{TiO}_{2}$ nanocomposite}

Graphene (G) was synthesized by the electrochemical graphite exfoliation method. First, a $1 \mathrm{M}$ sulfuric acid solution was prepared to subsequently place the electrodes that constitute the electrochemical array in a beaker. A graphite bar was used as a working electrode and a copper wire as a counter electrode. The operating voltage used was 12 Volts.

The synthesis of titanium dioxide (anatase) was performed using the sol-gel method [13], and it is described below: To start, $20 \mathrm{ml}$ of titanium butoxide was added to $200 \mathrm{ml}$ of distilled water in a beaker, which generated a white precipitate that was separated from the liquid by decantation. Then, the precipitate was redispersed in distilled water containing a $0.1 \mathrm{M}$ solution of nitric acid and glacial acetic acid in a 9/1 molar ratio (acetic acid/titanium butoxide). Subsequently, the graphene/ $\mathrm{TiO}_{2}$ nanocomposite was generated from the above-mentioned precursors through mixing with a

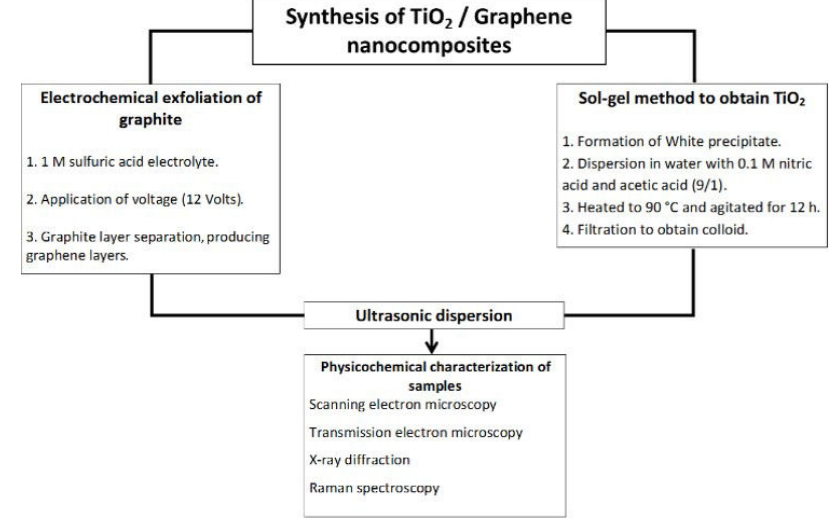

FIGURE 1. The experimental diagram to obtain graphene/ $/ \mathrm{TiO}_{2}$ nanocomposites.

50/50 wt \% ratio inside a cylindrical vial. After mixing, sonication was performed for one hour to disperse the respective phases. Figure 1 shows the complete methodology followed to obtain and characterize the $\mathrm{TiO}_{2} /$ graphene nanocomposite.

\subsection{Sample characterization}

The equipment used to identify the crystalline phases of the precursors was the X-ray diffraction system model D8 ADVANCE DAVINCI. The samples were analyzed with the conventional technique (Bragg-Brentano geometry). In general, the samples were run in a range of $2 \theta$ from $5^{\circ}$ to $80^{\circ}$, with a $0.2^{\circ}$ increase in the reading angle, every $0.5 \mathrm{sec}-$ onds. For the analysis of the morphology of the samples, several types of equipment were used: a JEOL brand Field Emission Scanning Electron Microscope (FESEM), model JSM 7600F in the secondary electron modes and topographic mode, a Transmission Electron Microscope (TEM), Tecnai Supertwin model with field emission. The instrument used to obtain the Raman spectrum of the graphene sample is a Bruker Optics Senterra Dispersive Microscope equipped with $532 \mathrm{~nm}, 785 \mathrm{~nm}$ and $633 \mathrm{~nm}$ laser. The configuration used was: $532 \mathrm{~nm}$ laser, $5 \mathrm{~mW}$ power, and 5 seconds of acquisition time. UV-vis spectroscopy was carried out on a Perkin Elmer (Lambda 25) spectrophotometer at wavelengths of 300-1100 $\mathrm{nm}$ to determine the bandgap energy of $\mathrm{TiO}_{2}$ nanoparticles.

\section{Results and Discussion}

\subsection{Raman spectroscopy to confirm the exfoliation of the graphite layers}

The Raman spectrums of the exfoliated graphene sample and the graphite precursor are shown in Fig. 2. The peaks obtained in the graphene sample correspond to the characteristic bands of graphene: D (1344), G (1569) D' (2689) G' (3220). Band D indicates the presence of defects or edges in graphene samples [14], which could be observed by SEM 


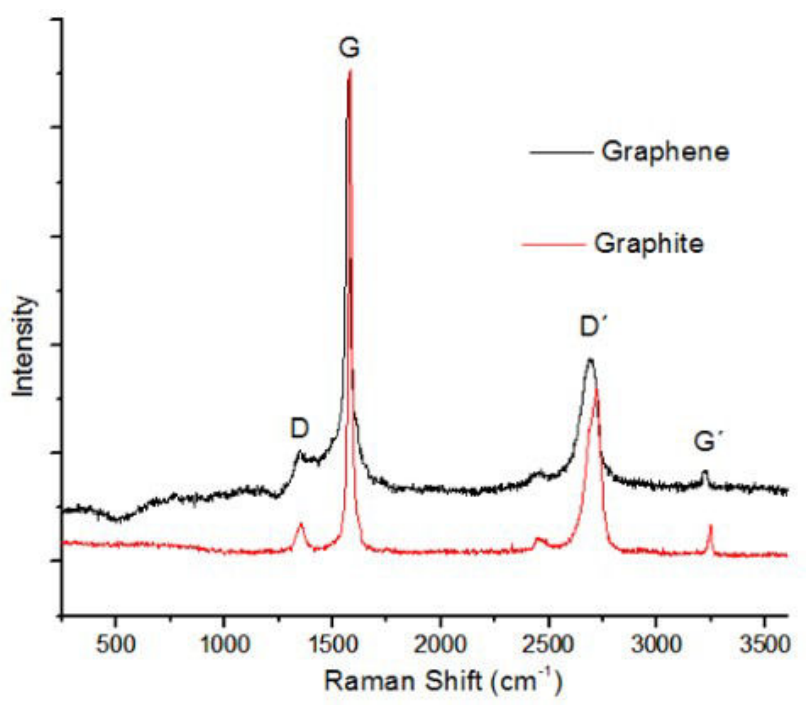

FIGURE 2. Raman spectrum of the graphene and graphite samples.

and TEM. The intensity of the G peak is relatively high, compared to the intensity that occurs in monolayer graphene samples, which is much lower. A slight shift to the left of the D' band after exfoliation can be observed. The D' band of monolayer graphene does not have sub-peaks, unlike bilayer graphene that has 4 sub-peaks and few-layer graphene and graphite that both have 2 sub-peaks [15]. The band D' in the graphene sample spectrum resembles that of graphene of a few layers, indicating the proper exfoliation of graphite layers.

\subsection{Identification of crystalline phases present in the graphene/ $\mathrm{TiO}_{2}$ nanocomposite}

The graph in Fig. 3 shows a comparison of the diffractograms obtained from anatase, graphene, and the $\mathrm{G} / \mathrm{TiO}_{2}$ nanocomposite. In the graphene precursor sample, the peak

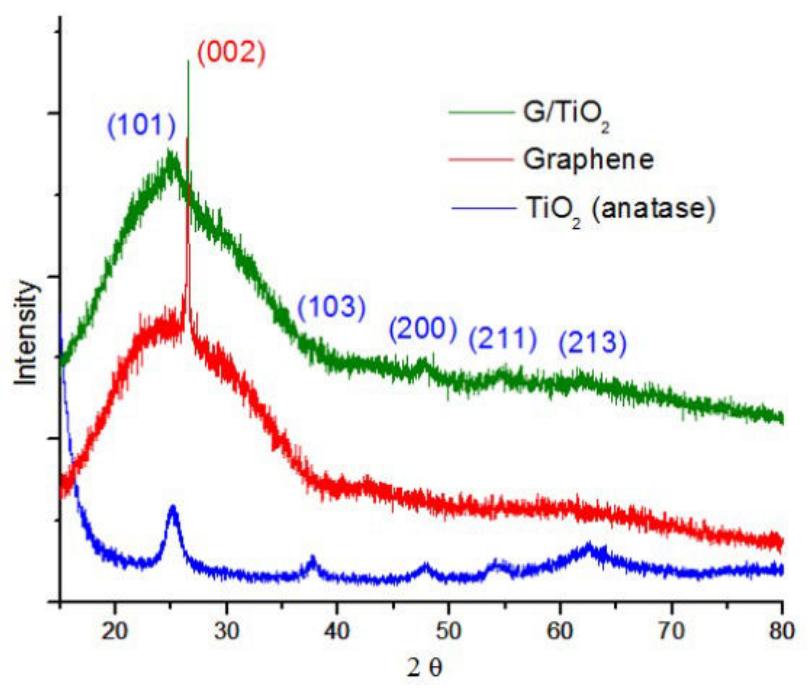

FIGURE 3. Comparison of the DRX patterns of graphene, anatase, and $\mathrm{G} / \mathrm{TiO}_{2}$ nanocomposite. at $2 \theta=26.4^{\circ}(002)$ is characteristic of graphite [16,17], and it may also be attributed to graphene or reduced graphene oxide. In the latter case, the peak is much wider, resembling an amorphous signal $[18,19]$.

The most relevant peak in the $\mathrm{TiO}_{2}$ sample obtained with the sol-gel method appears at around $25.3^{\circ}$, and it is characteristic of the crystalline phase of anatase [20]. Other peaks are also attributed to anatase and can be observed in the resulting diffractogram: $37.9^{\circ}(103), 47.7^{\circ}(200), 54.8^{\circ}$ (211) and $62.5^{\circ}(213)$. Both characteristic peaks of graphite and graphene, as well as the different $\mathrm{TiO}_{2}$ anatase peaks, are still present in the diffractogram of the anatase/graphene nanocomposite. Such nanocomposite corresponds to a mixture of anatase and graphene phases, and no chemical reaction has taken place that would have ended up in an additional phase. The average crystallite size of $\mathrm{TiO}_{2}$ nanoparticles was calculated to be around $6.14 \mathrm{~nm}$ by applying the Scherrer equation:

$$
D=\frac{k \lambda}{\beta \cos \theta},
$$

where $K$ is a dimensionless constant with a value close to unity, $\lambda$ is the $\mathrm{X}$-ray wavelength, $\beta$ is the full width at halfmaximum (FWHM) of the diffraction peak, and $\theta$ is the diffraction angle [21].

\subsection{Morphology of the graphene/ $\mathrm{TiO}_{2}$ nanocomposite}

Figure 4 shows the images obtained with the SEM of the synthesized composite. With high amplification (Fig. 4a), a graphene base with some $\mathrm{TiO}_{2}$ particles deposited on the surface can be observed, and some titania particles are below the graphene layers. The observed morphology is similar to that reported in the literature and corresponds to the physical mixture between the graphene and titania phases [22,23]. The EDS analysis with elemental mapping mode allows to distinguish the areas where each element is located. In Fig. 4b, the carbon is colored in red and titanium in green, the resulting mixture of both elements and, consequently, of both colors is shown in yellow. It can be noted that the most present color in the sample is yellow (a mixture of titanium and carbon), followed by areas where only green (titanium) is seen, and finally, some red dots (carbon). Besides a measurement of the green (titanium) and red (carbon) zones areas was carried out and nanometric particles of titanium (42 nm) and carbon (31 $\mathrm{nm})$ were measured.

The titania-graphene composite mixed by agitation and ultrasound was also analyzed with a Transmission Electron Microscope to observe the interaction between the crystalline phases of the precursors. In Fig. 5a an image is presented at very high amplification of the titaniagraphene composite, where different crystalline planes can be seen, as well as some amorphous areas. By performing a Fourier transform to this image, the pattern of dots and rings showed in Fig. $5 \mathrm{~b}$ is obtained, from which the different crystalline planes of the sample are indexed. From the rings 


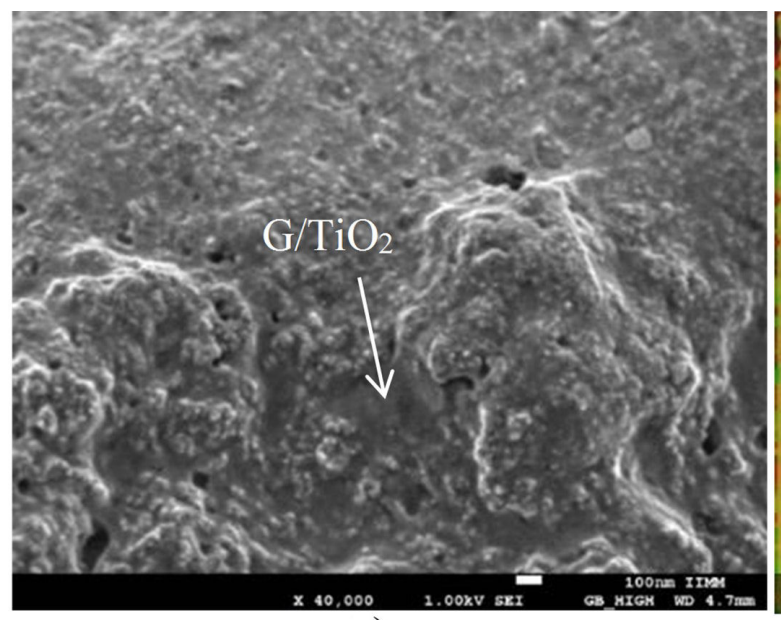

a)

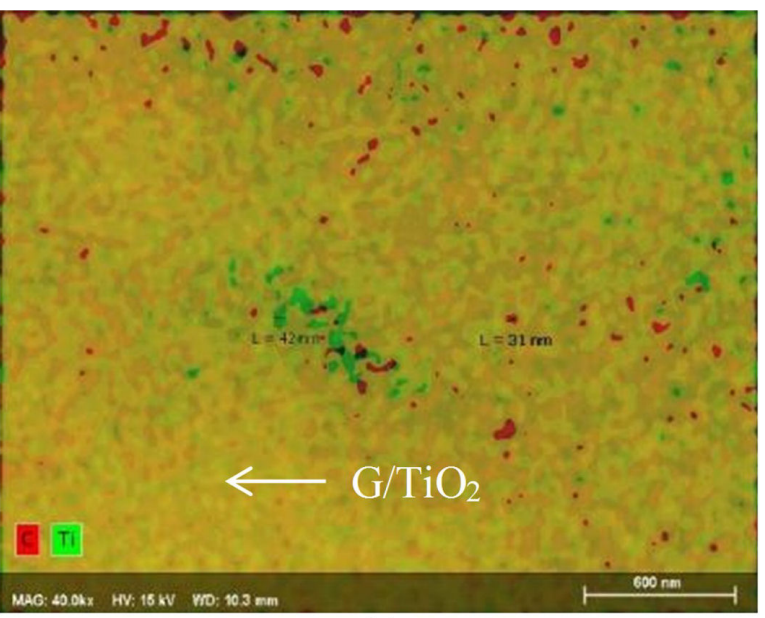

b)

FIGURE 4. FESEM images showing (a) the obtained $\mathrm{G} / \mathrm{TiO}_{2}$ nanocomposite at low magnification and (b) EDS maping of the same area showing the nano-scale dispersion and mixing of the $\mathrm{TiO}_{2}$ and graphene phases that constitute de nanocomposite.
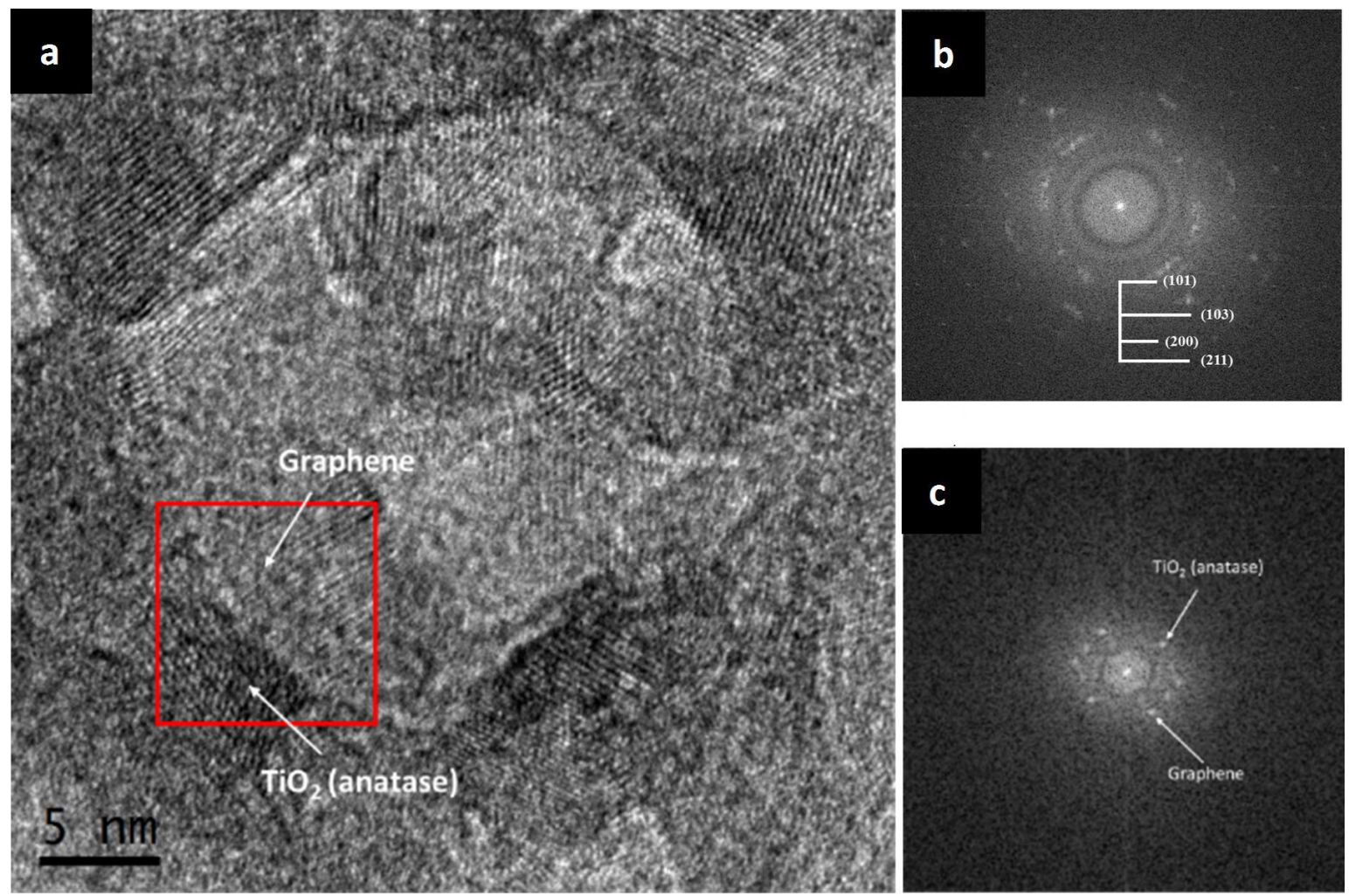

FIGURE 5. TEM images of the anatase and graphene composite mixed with ultrasound (a) general view of the nanocomposite at very high magnifications (b) ring pattern of the anatase crystalline planes, (c) point pattern corresponding to the graphene and $\mathrm{TiO}_{2}$ (anatase) phases.

displayed in the image and determining the interplanar distance to later compare with the databases, the presence of the planes (101), (103), (200), and (211), which correspond to the $\mathrm{TiO}_{2}$ (anatase) precursor is confirmed. The $\mathrm{TiO}_{2}$ nanoparticles have an average length of $6 \mathrm{~nm}$ and an average width of $4 \mathrm{~nm}$ according to measurements. The graphene diffraction points highlighted in the Fourier transform of Fig. 5c corresponds to an interplanar distance of approximately $0.344 \mathrm{~nm}$, which can be attributed to turbostrophic graphite according to the literature [24,25], that is to say, disordered graphite product of the electrochemical exfoliation process, which has an interplanar spacing greater than that of the ordered graphite $(0.335 \mathrm{~nm})$. This means than in the highlighted zone, few-layer graphene is present, alongside a $\mathrm{TiO}_{2}$ (anatase) nanoparticle with an interplanar spacing of $0.351 \mathrm{~nm}(101)$.

$\mathrm{TiO}_{2}$ nanoparticles were also measured from several TEM micrographs, and the average crystallite size was calcu- 


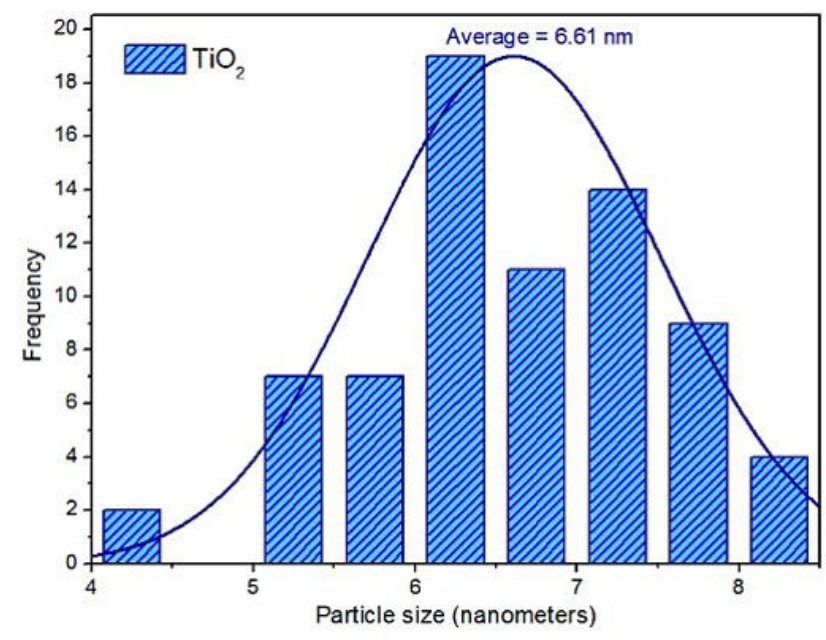

FIGURE 6. $\mathrm{TiO}_{2}$ statistical particle size distribution from TEM images measurements.

lated to be $6.61 \mathrm{~nm}$, as shown in Fig. 6, which is close to the value obtained from the Scherrer equation $(6.14 \mathrm{~nm})$. This extremely small $\mathrm{TiO}_{2}$ particle size, coupled with an enhanced transport of electrons on the highly conductive graphene phase, is expected to halt the recombination process of electrons and holes.

\subsection{Bandgap energies of $\mathrm{TiO}_{2}$ and graphene/ $\mathrm{TiO}_{2}$ nanocomposite}

The bandgap energies of $\mathrm{TiO}_{2}$ nanoparticles and $\mathrm{G} / \mathrm{TiO}_{2}$ nanocomposite were calculated using Tauc-relation [26,27], as shown in Fig. 7, where $\alpha$ is the absorption coefficient, and $h \nu$ is the photon energy, which is calculated with Eq. (2). In this equation, $\lambda$ is the wavelength in nanometers, $\mathrm{h}$ is the Planck's constant $\left(6.626 \times 10^{-34} \mathrm{Js}\right)$, and $c$ is the speed of light $\left(3 \times 10^{8} \mathrm{~m} / \mathrm{s}\right)$.

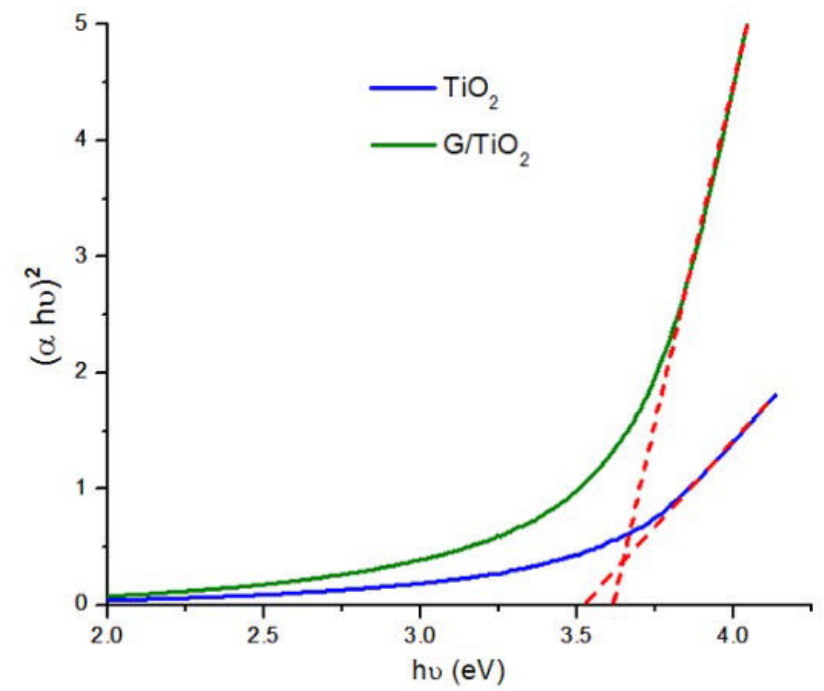

FIgURE 7. Bandgap energies of $\mathrm{TiO}_{2}$ nanoparticles and $\mathrm{G} / \mathrm{TiO}_{2}$ nanocomposite calculated using Tauc-relation.

$$
h \nu=\frac{h c}{\lambda}=\frac{1240}{\lambda} \mathrm{eV} .
$$

The value of $h \nu$ extrapolated to $\alpha=0$ gives and absorbs energy, which corresponds to a bandgap. For the $\mathrm{TiO}_{2}$ nanoparticles, the bandgap was calculated to be $3.54 \mathrm{eV}$, which is higher than $3.2 \mathrm{eV}$ for bulk $\mathrm{TiO}_{2}$ (anatase) [28]. This increase in the bandgap value occurs because the synthesized $\mathrm{TiO}_{2}$ nanoparticles have a relatively smaller size compared to bulk $\mathrm{TiO}_{2}$, and it is known that the decrease in particle size produces a larger bandgap [29]. The bandgap energy of $\mathrm{G} / \mathrm{TiO}_{2}$ nanocomposite was calculated to be $3.6 \mathrm{eV}$, which is practically the same bandgap value of the anatase phase. This similarity in bandgap values occurs presumably due to the high concentration of $\mathrm{TiO}_{2}$ nanoparticles surrounding the graphene flakes caused by electrostatic interactions. However it can be expected that in future studies, different concentration ratios of $\mathrm{TiO}_{2}$ and graphene in the nanocomposite will significantly decrease the combined bandgap, as this concentration ratio dependence on the bandgap value has been demonstrated in other graphene/ $\mathrm{TiO}_{2}$ nanocomposites [30-32].

\subsection{A theoretical model of graphene/ $\mathrm{TiO}_{2}$ nanocompos- ite}

Figure 8 shows a graphene/ $\mathrm{TiO}_{2}$ nanocomposite model that was developed from the TEM images. Anatase nanoparticles appear to aggregate around graphene flakes and also on the surface. This attraction between the two phases may be due to the positive charge in graphene and the negative charge in $\mathrm{TiO}_{2}$ particles, generating a weak bond, possibly Van der Waals, that does not generate a chemical reaction but does produce an aggregation of both nanomaterials.

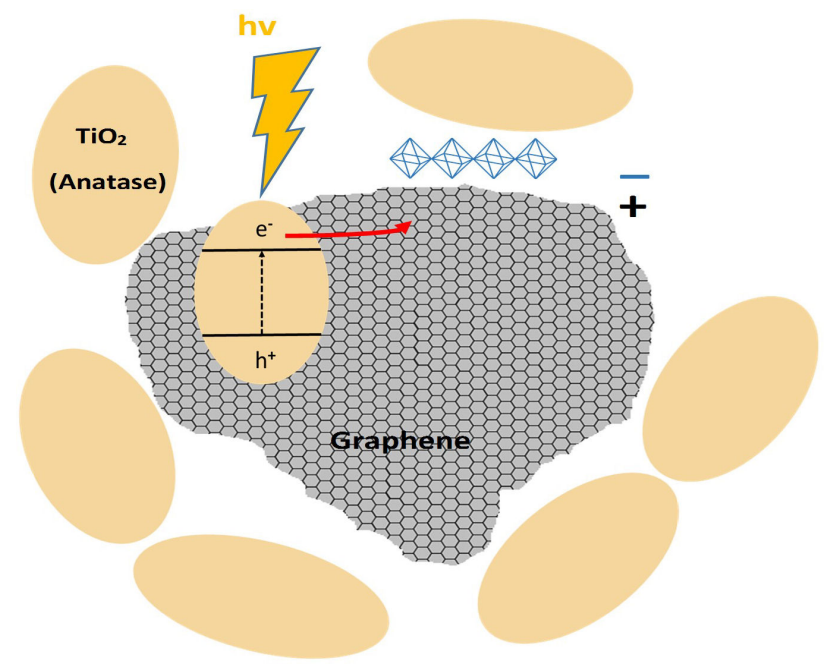

FIGURE 8. Graphene/ $\mathrm{TiO}_{2}$ nanocomposite model developed from TEM data. 


\section{Conclusions}

The obtained graphene/ $\mathrm{TiO}_{2}$ composite structure corresponds to the mechanical mixing of the graphene and titania phases on a nanometric scale, which was confirmed by electronic diffraction (MET), X-ray diffraction and highresolution field emission microscopy in chemical analysis mode. The Raman spectrum of the electrochemically exfoliated graphene sample allowed to confirm that the separation of the graphite layers was performed properly and few-layer graphene was obtained. The produced $\mathrm{TiO}_{2}$ has an extremely small particle size of around $6 \mathrm{~nm}$ which even though renders high bandgap energy, has a high specific surface area and provides the potential to stop the recombination process of electrons and holes coupled by an enhanced transport of electrons on the highly conductive graphene. The understanding of the obtained nanocomposite structure led to the development of a conceptual model that includes a two-phase composite held together by Vander Waals electrostatic forces in which the negative oxygen charges are attracted to the positive carbon forces of the graphene network. This nanocomposite configuration is expected to favor the energy collection by the anatase phase and the subsequent injection of generated electrons into the graphene network. Therefore, this nanomaterial may be promising in applications related to photocatalysis.

\section{Acknowledgments}

Authors acknowledge the financial support of the "Coordinación de la Investigación Científica de la Universidad Michoacana de San Nicolás de Hidalgo".
1. T. Lavanya, K. Satheesh, M. Dutta, N. V. Jaya, and N. Fukata, Superior photocatalytic performance of reduced graphene oxide wrapped electrospun anatase mesoporous $\mathrm{TiO} 2$ nanofibers, N. J. Alloys Compd. 615 (2014) 643, https://doi .org/ $10.1016 / j \cdot j a l l c o m .2014 .05 .088$

2. M. Li, G. Huang, Y. Qiao, J. Wang, and Z. Liu, Biocompatible and freestanding anatase $\mathrm{TiO}_{2}$ nanomembrane with enhanced photocatalytic performance, Nanotechnology 24 (2013) 305706, https://doi.org/10.1088/ 0957-4484/24/30/305706

3. E. X. Bingan Lu, Chengquan Zhu, Zhenxing Zhang, Wei Lan, Preparation of highly porous $\mathrm{TiO} 2$ nanotubes and their catalytic applications, J. Mater. Chem. 22 (2012) 1375, https: //doi.org/10.1039/C1JM15242D.

4. M. S. A. Sher Shah, A. R. Park, K. Zhang, J. H. Park, and P. J. Yoo, Green synthesis of biphasic TiO 2-reduced graphene oxide nanocomposites with highly enhanced photocatalytic activity, ACS Appl. Mater. Interfaces 4 (2012) 3893, https: //doi.org/10.1021/am301287m

5. H. J. Choi et al., Graphene for energy conversion and storage in fuel cells and supercapacitors, Nano Energy 1 (2010) 534, https://doi.org/10.1016/j.nanoen.2012. 05.001 .

6. F. Liu, C. W. Lee, and J. S. Im, Graphene-Based Carbon Materials for Electrochemical Energy Storage, J. Nanomater. 2013 (2013) 1, https://doi.org/10.1155/2013/642915

7. E. L. Wolf, "Applications of Graphene: An Overview" Springer, New York, (2014), https://doi.org/10. 1007/978-3-319-03946-6.

8. W. Geng, H. Liu, and X. Yao, Enhanced photocatalytic properties of titania-graphene nanocomposites: a density functional, Phys. Chem. Chem. Phys. 15 (2013) 6025, https://doi. org/10.1039/C3CP 43720E

9. H. Liu et al., Graphene Grown on Anatase-TiO2 Nanosheets: Enhanced Photocatalytic Activity on Basis of a WellControlled Interface, J. Phys. Chem. C 122 (2018) 6388, https://doi.org/10.1021/acs.jpcc.7b12305.
10. L. Bai et al., A sandwich structure of mesoporous anatase $\mathrm{TiO} 2$ sheets and reduced graphene oxide and its application as lithium-ion battery electrodes, RSC $A d v .4$ (2014) 43039, https://doi.org/10.1039/C4RA04979A

11. U. S. Heo, D. W. Kim, K. S. Kim, and D. W. Park, A facile synthesis of anatase TiO 2 -Graphene nanocomposites using plasma and heat treatment, Appl. Surf. Sci. 474 (2019) 118, https://doi.org/10.1016/j.apsusc.2018. 04.083

12. L. Chen, S. Yang, L. Mu, and P. Ma., Three-dimensional titanium dioxide/graphene hybrids with improved performance for photocatalysis and energy storage, J. Colloid Interface Sci. 512 (2017) 647, https: //doi.org/10.1016/j.jcis. 2017.10 .103

13. O. Muñiz-Serrato and J. Serrato-Rodríguez, Nanostructuring anatase through the addition of acetic acid by the sol-gel low temperature aqueous processing, J. Ceram. Int. 40 (2014) 8631, https://doi.org/10.1016/j. ceramint.2014.01.080

14. Z. Tu et al., Controllable growth of 1-7 layers of graphene by chemical vapour deposition, Carbon N. Y. 73 (2014) 252, https://doi.org/10.1016/j.carbon.2014. 02.061

15. D. Graf, F. Molitor, K. Ensslin, and C. Stampfer, Spatially resolved Raman spectroscopy of single-and few-layer graphene, Nano Lett. 7 (2007) 238, https://doi.org/10.1021/ n1061702a.

16. Z. Q. Li, C. J. Lu, Z. P. Xia, Y. Zhou, and Z. Luo, X-ray diffraction patterns of graphite and turbostratic carbon, Carbon N. Y. 45 (2007) 1686, https://doi.org/10.1016/j. carbon.2007.03.038.

17. D. Kim, S. J. Yang, Y. S. Kim, H. Jung, and C. R. Park, Simple and cost-effective reduction of graphite oxide by sulfuric acid, Carbon N. Y. 50 (2012) 3229, https://doi.org/ $10.1016 / j . c a r b o n .2011 .11 .014$ 
18. H. Ding et al., Reduction of graphene oxide at room temperature with vitamin $\mathrm{C}$ for $\mathrm{RGO}-\mathrm{TiO}_{2}$ photoanodes in dyesensitized solar cell, Thin Solid Films 584 (2015) 29, https : //doi.org/10.1016/j.tsf.2015.02.038

19. C. Xu, R. Yuan, and X. Wang, Selective reduction of graphene oxide, New Carbon Mater. 29 (2014) 61, https://doi. org/10.1016/S1872-5805(14)60126-8

20. R. K. Wahi, Y. Liu, J. C. Falkner, and V. L. Colvin, Solvothermal synthesis and characterization of anatase $\mathrm{TiO} 2$ nanocrystals with ultrahigh surface area, J. Colloid Interface Sci. 302 (2006) 530, https: //doi.org/10.1016/j.jcis. 2006.07 .003

21. X. Chen and S. S. Mao, Titanium dioxide nanomaterials: Synthesis, properties, modifications and applications, Chem. Rev. 107 (2007) 2891, https://doi.org/10.1021/ Cr0500535.

22. Y. L. Zhong, Z. Tian, G. P. Simon, and D. Li, Scalable production of graphene via wet chemistry: Progress and challenges, Mater. Today 18 (2015) 73, https://doi.org/ $10.1016 / j . m a t t o d .2014 .08 .019$

23. T. N. Lambert et al., Synthesis and Characterization of Titania - Graphene Nanocomposites, J. Phys. Chem. C 113 (2009) 19812, https://doi.org/10.1021/jp905456f

24. M. A. Pimenta et al., Studying disorder in graphite-based systems by Raman spectroscopy, Phys. Chem. Chem. Phys. 9 (2007) 1276, https://doi.org/10.1039/B613962K

25. S. Dimovski, A. Nikitin, H. Ye, and Y. Gogotsi, Synthesis of graphite by chlorination of iron carbide at moderate temperatures, J. Mater. Chem. 14 (2004) 238, https://doi.org/ $10.1039 / \mathrm{B} 311938 \mathrm{~F}$
26. A. Katoch, R. Bhardwaj, N. Goyal, and S. Gautam, Synthesis, structural and optical study of Ni-doped Metal-organic framework for adsorption based chemical sensor application, $\mathrm{Vac}$ uum 158 (2018) 249, https://doi.org/10.1016/j. vacuum.2018.09.019.

27. H. Liu, G. Zhang, W. Sun, Z. Shen, and M. Shi, ZnO hierarchical nanostructure photoanode in a CdS quantum dot-sensitized solar cell, PLoS One 10 (2015) 9, https : / / doi .org/10. $1371 /$ journal.pone.0138298

28. D. Reyes-Coronado et al., Phase-pure $\mathrm{TiO}_{2}$ nanoparticles: Anatase, brookite and rutile, Nanotechnology 19 (2008) 145605, https://doi.org/10.1088/0957-4484/ $19 / 14 / 145605$

29. S. Bagheri, K. Shameli, S. Bee, and A. Hamid, Synthesis and Characterization of Anatase Titanium Dioxide Nanoparticles Using Egg White Solution via Sol-Gel Method, J. Chem. 2013 (2013), https://doi.org/10.1155/2013/848205

30. M. Faraldos and A. Bahamonde, Environmental applications of titania-graphene photocatalysts, Catal. Today 285 (2017) 13, https://doi.org/10.1016/j.cattod. 2017.01 .029

31. W. Fan, Q. Lai, Q. Zhang, and Y. Wang, Nanocomposites of $\mathrm{TiO}_{2}$ and reduced graphene oxide as efficient photocatalysts for hydrogen evolution, J. Phys. Chem. C 115 (2011) 10694, https://doi.org/10.1021/jp2008804

32. H. Zhang, X. Lv, Y. Li, Y. Wang, and J. Li, P25-Graphene Composite as a High Performance Photocatalyst, ACS Nano 4 (2009) 380, https : //doi .org/10.1021/nn901221k 